\title{
TIME-DEPENDENT DEFLECTION OF PRESTRESSED AND NON-PRESTRESSED FRP-STRENGTHENED STRUCTURES
}

\author{
H. M. Diab ${ }^{1}$ and Mamdouh Abass ${ }^{2}$ \\ ${ }^{1}$ Department of Civil Engineering, Assiut University, Egypt \\ ${ }^{2}$ Department of Civil Engineering, Sohag University, Egypt
}

(Received February 25, 2010 Accepted March 24, 2010).

\begin{abstract}
External bonding of fiber reinforced polymer (FRP) sheets has been proven to be an effective method to strengthen and retrofit deteriorated or damage RC or PC structures. However, the long-term serviceability of such FRP-strengthened beams is still a concern due to lack of long-term performance data especially for prestressed FRP sheets. This study presents a manual method for predicting the short-term and timedependent deflections for RC beams strengthened by prestressed or nonprestressed FRP sheets. The age-adjusted effective modulus method is used to model the creep behavior in concrete and the relaxation in FRP prestressing sheets. A tension-stiffening model is presented to evaluate the stiffness of the cracked section. The analytical values are compared to the results obtained from a finite element code, and to the experimental results from some existing papers. It is found that the analytical method is in a good agreement with finite element methods.
\end{abstract}

KEYWORDS: Fiber reinforced polymer, concrete, time dependent deflection, prestressed FRP sheets, creep.

\section{INTRODUCTION}

Serviceability of concrete can be defined as satisfactory performance under service load conditions which in turn can be described in terms of two parameters-cracking and deflection. Deflections constitute one of the important serviceability criteria in the design of concrete structures. To keep the deflection of reinforced concrete (RC) members within allowable limits, some control mechanisms, such as appropriate design and construction procedures and the use of appropriate materials like short fiber reinforcements to provide higher beam stiffness and better crack control, have been recommended by ACI Committee 435 (1995).

Recently, Diab and Wu (2007, 2008) and Wu and Diab (2007) proposed a viscoelastic model and revealed that it is possible to estimate the time-dependent behavior with regard to the adhesive layer bonding of the interface between concrete and the FRP sheet. Tan and Saha (2006) conducted a study on the characteristics of the time-dependant deflection of RC beams externally bonded with FRP. However, the former study concerned only on the time-dependant behavior characteristics of the interface model with regard to the FRP sheet, while the latter study concentrated only on the time-dependant deflection of RC beams with externally bonded FRP. In order to predict a significantly more reasonable time-dependant behavior, a stress-strain relationship within the FRP-strengthened beam should first be clarified. 
The use of prestressed fiber reinforced polymers (FRP) sheets in reinforcement concrete has been used for several structures and bridges as a solution of the corrosion problem [Wu et al. (2000) and Diab et al. (2009)]. This material represents a relatively new technology; therefore much research is needed to introduce a simplified method to calculate the short and long-term deflections of these structures.

This paper presents a general simplified method for calculating displacements in prestressed and non-prestressed reinforced concrete with FRP sheet. The method is based on the analysis of strain distribution at individual sections to determine axial strain and curvature under prescribed loading condition. Starting with the calculation of axial strain and curvature at individual sections, the variation of these parameters over the length of members is determined and used to calculate the translations or rotations at any section. The comprehensive analysis requires more calculations than the simplified methods and also requires more input data. The comprehensive analysis is recommended when the deflection is critical and accuracy is necessary. The general method in this paper determines the displacements in prestressed and nonprestressed reinforced concrete plane frames. This method is based on an analysis of strain distribution at a section considering the effects of a normal force and a moment caused by applied loads, prestressing, creep and shrinkage of concrete, and relaxation of prestressing FRP sheets. The calculated axial strain and the curvature at various sections of the frame can then be used to calculate displacement by virtual work or other classical technique. The sectional analysis can accommodate the effect of creep and shrinkage of concrete and relaxation of prestressing FRP sheets.

The sectional analysis is intended for service conditions. A linear stress-strain relationship can be assumed for the concrete under service conditions, provided that the concrete stress does not exceed about the half the compressive strength (ACI 435R95 2003). The procedure presented in this paper is intended to compute deformation in service; it does not track the behavior as the load approaches ultimate.

ACI 440 (2001) summarized the studies carried out so far on the deflection of FRP-reinforced concrete reinforced with FRP bars and provides a guide to calculate the effective moment of inertia for cracked section. By taking into account the effect of concrete tension stiffening, the guide also discussed the long-term deflection. Also, ACI 440.2R-02 (2002) summarized the studies for structures reinforced with nonprestressed FRP-sheets.

This paper provides a simplified procedure to calculate the long-term deflection of structures strengthening by prestressed or nonprestressed FRP-sheets including creep and shrinkage of concrete beside the relaxation of prestressing FRP sheets. This method has been validated against the results from a Two-dimensional FE analysis presented by the 1990 European CEB-FIP code and experimental results from some existing papers.

\section{TIME-DEPENDENT PROPERTIES OF MATERIALS}

The material time-dependent parameters required to calculate the deformations of the concrete structures are as follows: 


\section{Creep of Concrete}

The creep coefficient of concrete depends on the concrete compressive strength, relative humidity of the environment as well as the age of concrete at the time of loading. There have been many model proposed to determine the development creep and shrinkage over time. The guidance to calculate the creep values to be used in design for exact solution is given in ACI 209R, CEB-FIP1990 and Dutch NEN 6720 code. However, to simplify the calculation, equation 1 can be used to obtain the creep value of concrete. This equation does not give the exact value as previous models but shows a good agreement with CEB-FIP 1990 model.

$$
\begin{aligned}
& C_{t}=2.75 \beta \frac{t^{0.6}}{\left(10+t^{0.6}\right)} \\
& \beta=\frac{41.83}{\sqrt{R H \times f_{c}}}
\end{aligned}
$$

Where; $t$ is the time (in days) after applied loads, $\beta$ is the correction factor for ambient relative humidity $\mathrm{RH}$, and for the 28 day compressive strength of concrete $f_{c}$.

\section{Shrinkage of Concrete}

If the concrete members were free to shrink, without restraint, shrinkage of concrete would not be a major concern to structural engineers. However, this is not the case. The contraction of a concrete member is often restrained by its supports or by the adjacent structure. Bonded reinforcement and FRP sheet also restraint shrinkage. The strain resulted from restraint shrinkage $\varepsilon_{S H}\left(t, t_{0}\right)$ depends on many factors and can be calculated by the same codes used for creep.

\section{Creep of FRP Sheets}

The creep coefficient of FRP is defined as the ratio of creep strain to elastic strain under a constant sustained stress. The creep coefficient of various FRP tendons has been studied recently (Zou 2003). It was concluded that the relaxation of CFRP tendon can be considered to be zero as obtained from others also. In the case of an AFRP tendon the creep reach to $15 \%$ and this result agree with many researchers.

The following empirical equation was used to model the creep coefficient of AFRP tendon (Zou 2003).

$$
\phi_{p t}=0.0058 \ln (24 t)+.0531
$$

\section{INSTANTANEOUS ANALYSIS}

\section{Uncracked Section}

At the service load level, the short-term analysis of a cross section can be carried by transforming the bonded reinforcement and FRP sheet into equivalent areas of concrete and performing a simple elastic analysis on the equivalent concrete section. In the transformation, $\mathrm{n}_{\mathrm{p}}$ is called the modulus ratio for FRP sheet and $n_{p}=E_{p} / E_{c}$, where $E_{p}$ and $E_{c}$ are the elastic modulus of FRP sheet and concrete, respectively. The 
corresponding modulus ration for the conventional nonprestressed reinforcement is designated ns and $n_{s}=E_{s} / E_{c}$. The area $\mathrm{A}$, the first and second moments $\mathrm{B}$ and I of the transformed section are taken about the top fiber of the section at point $\mathrm{O}$ as shown at figure 1. Choosing $\mathrm{O}$ at a fixed point (for example, the top fiber) rather than the centroid has the advantage the location of the centroid does not have to be determined for the cracked and uncracked stages. The initial strain and stress distribution on uncracked sections are assumed to be linear over the depth of the section.

When external loading $\mathrm{N}$ and $\mathrm{M}$ are known, the corresponding strain and stress parameters are given by (ACI 435R-95).

$\varepsilon_{O}\left(t_{0}\right)=\frac{I N-B M}{E_{c}\left(A I-B^{2}\right)}$

$k\left(t_{0}\right)=\frac{-B N+A M}{E_{c}\left(A I-B^{2}\right)}$

$\sigma_{O}\left(t_{0}\right)=E \varepsilon_{O}$

$\gamma\left(t_{0}\right)=E k$

where; $\varepsilon_{O}, \sigma_{O}$ are the strain and stress at $\mathrm{O}$, and $\mathrm{k}$ is the curvature of beam, and $\gamma=d \sigma / d y$.

The concrete strain $\varepsilon_{y}$ and stress $\sigma_{y}$ at y below the top fiber at any time are

$\varepsilon_{y}=\varepsilon_{O}+y k$

$\sigma_{y}=E_{c}\left(\varepsilon_{O}+y k\right)$

the corresponding stresses in the reinforcement at FRP sheet can be determined using the linear material properties.
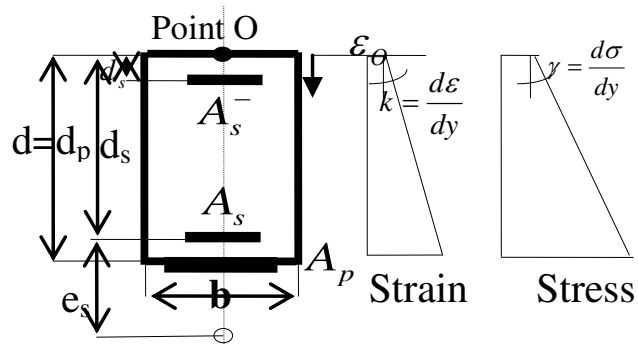

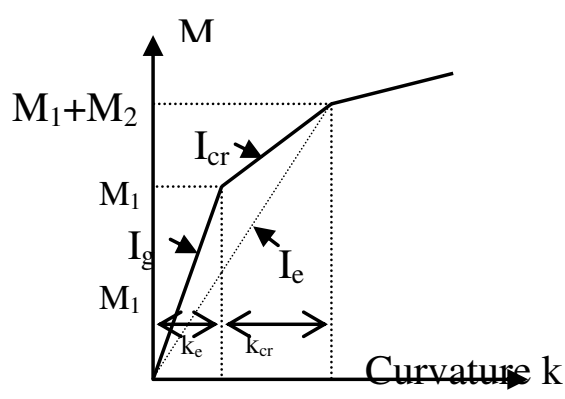

Figure2: moment curvature relation stress distribution in a cross section

\section{Cracked Section}

In a cracked section, the tensile stress of concrete exceeds the flexural tensile stress $f_{t}$, due to the application of external loads $\mathrm{M}$ and $\mathrm{N}$ to the prestressed beam. In this case, 
the calculation can be carried out using bilinear computation method by partitioning $\mathrm{M}$ and $N$ into two parts, such as $M=M_{1}+M_{2}$ and $N=N_{1}+N_{2}$. The pair $N_{1}$ and $M_{1}$ represent the stress resultants that will bring to zero the concrete stresses existing before the introduction of $\mathrm{M}$ and $\mathrm{N}$; the pairs $\mathrm{N}_{2}$ and $\mathrm{M}_{2}$ represent the remainder. With $\mathrm{N}_{1}$ and $\mathrm{M}_{1}$, the section remain uncracked whereas, cracking is produce only when $\mathrm{N}_{2}$ is combined with $\mathbf{M}_{2}$. For the analysis purpose, two loading stages is needed to be considered. Firstly, $\mathrm{N}_{1}$ and $\mathrm{M}_{1}$ are applied on an uncracked section and finally $\mathrm{N}_{2}$ and $\mathrm{M}_{2}$ are applied on a cracked section, in which the concrete outside the compression zone is ignored the strains in the two stages-deflection- are added to give the total instantaneous change as shown at figure 2 . The values of $\mathrm{N}_{1}$ and $\mathrm{M}_{1}$ are given by

$N_{1}=A \sigma_{o}+B \gamma$

$M_{1}=B \sigma_{O}+I \gamma$

where; $\sigma_{O}$ and $\gamma$ the initial stress before applying the load $\mathrm{M}$ and $\mathrm{N}$ with reversed sign, and $\mathrm{A}, \mathrm{B}$, and I properties of uncracked transformed section.

After $\mathrm{N}_{1}$ and $\mathrm{M}_{1}$ have been determined, $\mathrm{N}_{2}$ and $\mathrm{M}_{2}$ are calculated by $\mathrm{N}_{2}=\mathrm{N}-\mathrm{N}_{1}$ and $\mathrm{M}_{2}=\mathrm{M}-\mathrm{M}_{1}$. These loads are then applied on a reinforced concrete crack section, the properties of crack section $\mathrm{A}_{\mathrm{cr}}, \mathrm{B}_{\mathrm{cr}}$, and $\mathrm{I}_{\mathrm{cr}}$ can be determined after calculating the $\mathrm{c}$, the depth of compression concrete zone. For the cross section subjected to $\mathrm{N}$ and $\mathrm{M}$, the depth of compression zone can easily be calculated (Ghali and Favre 2002).

$$
\begin{aligned}
b\left(\frac{1}{2} c^{2}\right)\left(d_{s}-\right. & \left.\frac{1}{3} c\right)+\left(n_{s}-1\right) A_{s}^{-}\left(c-d_{s}^{-}\right)\left(d_{s}-d_{s}^{-}\right)-n_{p} A_{p}\left(d_{p}-c\right)\left(d_{s}-d_{p}\right) \\
+ & e_{s}\left[b \frac{c^{2}}{2}+\left(n_{s}-1\right) A_{s}^{-}\left(c-d_{s}^{-}\right)-n_{p} A_{p}\left(d_{p}-c\right)-n_{s} A_{s}\left(d_{s}-c\right)\right]=0
\end{aligned}
$$

The dimensions of the cross section are shown in figure 1.

\section{Tension stiffening}

Since concrete has the ability to carry tensile stress between cracks in the tension zone due to the bond between the reinforcement-bars and FRP sheet, a tension stiffening model is used in the cracked cross-sectional analysis of beams or frames. The tension stiffening model has been proposed for prestressed or nonprestressed reinforced concrete section by CEB FIP model code (1990). The mean strain parameters $\varepsilon_{O m}$ and $k_{m}$ can be determined by interpolation between uncracked and cracked states

$\varepsilon_{O m}=(1-\zeta) \varepsilon_{O 1}+\zeta \varepsilon_{O 2}$

$k_{O m}=(1-\zeta) k_{O 1}+\zeta k_{O 2}$

where; $\varepsilon_{O 1}$ and $k_{1}$ are strain parameters calculated using uncracked transformed section, and $\varepsilon_{\mathrm{O}_{2}}$ and $k_{2}$ are strain parameters calculated using the cracked transformed section. $\zeta$ is an empirical interpolation coefficient and is given by

$\zeta=1-\beta\left(\frac{f_{c t}}{\sigma_{t \max }}\right)^{2}$ 
where; $f_{c t}$ is the tensile strength of concrete, $\sigma_{t \text { max }}$ is the calculated tensile stress at extreme fiber when cracking is ignored and it must be greater than $f_{c t} \cdot \beta$ is a coefficient to account for the effect of bond quality of reinforcement, cyclic, and sustained loading on tension stiffening.

In most cases, $\beta=0.5$ can be used when deformed bars are employed and 1.0 when cyclic or sustained loads are applied.

It should be pointed out that the coefficient $\beta$ was derived for prestress or nonprestressed bars, not for prestressed FRP sheet. So, further studies are needed to investigate the value of $\beta$ for FRP sheet.

\section{TIME-DEPENDENT ANALYSIS OF CROSS SECTION}

The time analysis of the cross section considered in this paper use the age-adjusted effective modulus methods (AEMM) together with relaxation approach. After calculating the instantaneous strain parameters, $\Delta \varepsilon_{O}\left(t_{0}\right)$ and $\Delta k\left(t_{0}\right)$ (from equation 4 and 5 for under cracked section or equation 13 and 14 for cracked section) and the instantaneous changes in the stress parameters $\Delta \sigma_{O}\left(t_{0}\right)$ and $\Delta \gamma\left(t_{0}\right)$; the parameters for the hypothetical strain change that would occur in the period $t_{0}$ to $t$, if creep and shrinkage were unrestrained are obtained as follows:

$\Delta \varepsilon_{\text {free }}\left(t, t_{0}\right)=\varepsilon_{S H}\left(t, t_{0}\right)+C_{t} \Delta \varepsilon_{O}\left(t, t_{0}\right)$

$\Delta k_{\text {free }}=C_{t}\left(t, t_{0}\right) \Delta k\left(t_{0}\right)$

However, if it is assumed that the creep and the shrinkage are restrained, then the two parameters defining the distribution of hypothetical stress gradually introduced between time $t_{0}$ and $t$ to prevent the strain change are calculated by (ACI $435 \mathrm{R}$ 95)using;

$$
\begin{aligned}
& \sigma_{O_{\text {restraint }}}=-E_{e c} \Delta \varepsilon_{O \text { free }} \\
& \gamma_{\text {restraint }}=-E_{e c} \Delta k_{\text {free }}
\end{aligned}
$$

where; $\mathrm{E}_{\mathrm{ce}}$ is the age-adjusted modulus of elasticity of concrete and,

$E_{e c}\left(t, t_{0}\right)=E_{c}(t) /\left[1+X C_{t}\left(t, t_{0}\right)\right]$

$E_{e p}\left(t, t_{0}\right)=E_{p}(t) /\left[1+\phi_{p t}\left(t, t_{0}\right)\right\rfloor$

where $\mathrm{X}$ is the aging coefficient and is equal to 0.8 (ACI 209R). $\mathrm{E}_{\mathrm{ep}}$ is the age-adjusted modulus of elasticity of FRP sheet

This procedure is also suitable for FRP sheets (Zou 2003) hence, the resultants of stress required to prevent creep and shrinkage deformation are:

$$
\begin{aligned}
& \Delta N_{\text {creep, shrinkage }}=A_{c} \sigma_{O \text { restraint }}+B_{c} \gamma_{\text {restraint }}+A_{p} \sigma_{O \text { restraint }}+B_{p} \gamma_{\text {restraint }} \\
& \Delta M_{\text {creep, shrinkage }}=B_{c} \sigma_{O \text { restraint }}+I_{c} \gamma_{\text {restraint }}+B_{p} \sigma_{O \text { restraint }}+I_{p} \gamma_{\text {restraint }}
\end{aligned}
$$

where; $A_{c}, B_{c}$, and $I_{c}$ are the properties of concrete alone without reinforcement, $A_{p}, B_{p}$, and $I_{p}$ are the properties of FRP sheet at point $O$. 
Eliminate the fictitious restraint by applying $-\Delta N$ and $-\Delta M$ on the ageadjusted transformed section and the calculated changes in strain and stress parameters from equations 4 and 5 are:

$$
\begin{aligned}
& \Delta \varepsilon_{o}(t)=\frac{I_{e}(-\Delta N)-B_{e}(-\Delta M)}{E_{e c}\left(A_{e} I_{e}-B_{e}{ }^{2}\right)} \\
& \Delta k(t)=\frac{-B_{e}(-\Delta N)+A_{e}(-\Delta M)}{E_{e c}\left(A_{e} I_{e}-B^{2}\right)}
\end{aligned}
$$

where; $A_{e}, B_{e}$, and $I_{e}$ are the properties of the age-adjusted transformed section using the modular ratios of the age-adjusted transformed section are given by $n_{e s}=E_{s} / E_{c}(t)$ and $n_{e p}=E_{p}(t) / E_{c}(t)$ and are used to determine the transformed area of FRP sheet and reinforcement respectively.

The time-dependent change of stress parameters of concrete at the end of time are

$$
\begin{aligned}
& \Delta \sigma_{O}(t)=\sigma_{O \text { restraint }}+E_{e c} \Delta \varepsilon_{O}(t) \\
& \Delta \gamma_{O}(t)=\gamma_{O \text { restraint }}+E_{e c} \Delta k(t)
\end{aligned}
$$

After the time-dependent changes of strains, curvatures and stresses are determined, the final strains curvatures, and stresses at the cross section are readily found by

$$
\begin{aligned}
& \varepsilon_{O}(t)=\varepsilon_{O}\left(t_{0}\right)+\Delta \varepsilon_{O}(t) \\
& k_{O}(t)=k_{O}\left(t_{0}\right)+\Delta k_{O}(t) \\
& \sigma_{O}(t)=\sigma_{O}\left(t_{0}\right)+\Delta \sigma_{O}(t) \\
& \gamma_{O}(t)=\gamma_{O}\left(t_{0}\right)+\Delta \gamma_{O}(t)
\end{aligned}
$$

\section{Deflection Calculation}

When the load induced and creep and shrinkage induced curvatures are calculated at selected sections along a beam or frame, the deflection at midspan can be obtained by double integration of the curvatures. For a reinforced or prestressed concrete continuous span with the degree of cracking varying along the member, the curvature at the left and right supports, $\mathrm{k}_{\mathrm{l}}$ and $\mathrm{k}_{\mathrm{r}}$ and the curvature at midspan $\mathrm{k}_{\mathrm{m}}$ may be calculated at any time after loading and the deflection at midspan $\delta_{\text {midspan }}$ may be approximated by assuming a parabolic curvature diagram along the span, $l$

$$
\delta_{\text {midspan }}=\frac{l^{2}}{96}\left(k_{l}+10 k_{m}+k_{r}\right)
$$

the above equation will give a reasonable estimate of deflection even when the curvature diagram is not parabolic and is a useful expression for use in deflection calculation (Gilbert 2001).

\section{METHOD VERIFICATION}

To ascertain the validity of the proposed method, a comparison between finite element method using a commercially available FEA code DIANA and experimental results with the proposed method has been used. 


\section{FINITE ELEMENT VERIFICATION}

\section{Detail description of FEA model.}

A two dimensional FE analysis is carried out for the simple supported beam.. Figure 3 shows the dimensions and details of the beam. The FRP strengthened beam is modeled using plain stress elements for the concrete (4 nodded Q8MEM), The prestressed FRP sheets were represented by truss element (L2TRU). Moreover, embedded bar element is used to represent the reinforcement bars. It is assumed perfect bonding between FRP sheets and concrete to avoid the effect of adhesive creep. The beam is strengthened by two layers of FRP sheets, $100 \mathrm{~mm}$ wide and thickness of $0.128 \mathrm{~mm}$, the prestressing level is $33 \%$ of FRP tensile strength ( $\sigma_{\text {ultimate }}=3400 \mathrm{MPa}$ ). The beam is loaded at 63 day after releasing the prestressing load at midspan by one concentrated load $\mathrm{P}=15.0$ $\mathrm{kN}\left(<\mathrm{P}_{\mathrm{cr}}\right)$. The material properties are

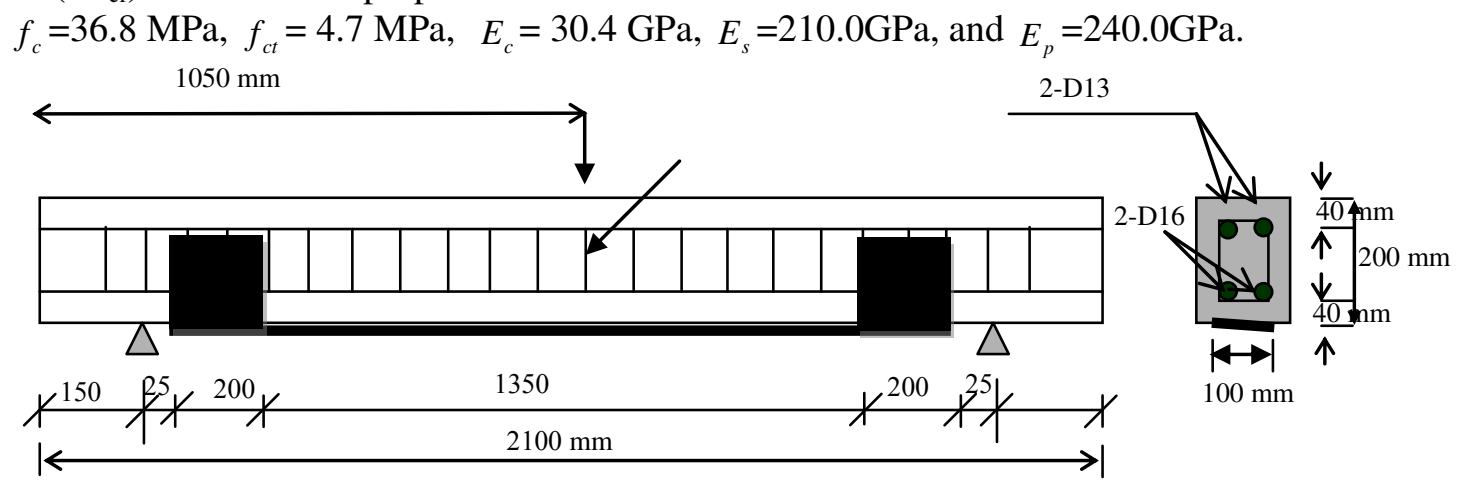

Fig. 3 Dimensions and details of the beam

Figure 4 shows the long-term midspan displacements for the two models, proposed model and FE model. From this figure it can be noticed that there is an excellent agreement between two models, which indicates that the proposed model is very useful to calculate the long term deflection of beam strengthened by FRP sheets. It should be pointed out that the creep and shrinkage, CEB-FIP Model Code 1990, are used for both analyses with the same data. The initial camber is $-0.299 \mathrm{~mm}$ from proposed model ( $-0.306 \mathrm{~mm}$ FE model) and it increases with time to $-0.534 \mathrm{~mm}$ ($0.549 \mathrm{~mm})$ at time 63 days. Upon loading the deflection increased to $0.082 \mathrm{~mm}(.094)$ (downward). With time the deflection increased continuously and it reaches $0.81 \mathrm{~mm}$ (0.77) which is about 2.17 times of the instantaneous deflection. These values have a strong relation with relative ambient humidity $(\mathrm{RH})$ at this study $\mathrm{RH}=50 \%$ is considered. Also, these values depend on many parameters such as creep of FRP sheet itself, prestressing level of FRP sheet, creep at adhesive, and tension stiffening at the case of cracking loads. Hence, furthers studies are necessary to investigate the timedependent behavior of structures strengthened by prestressed FRP sheets considering the effects of above mentioned factors. 


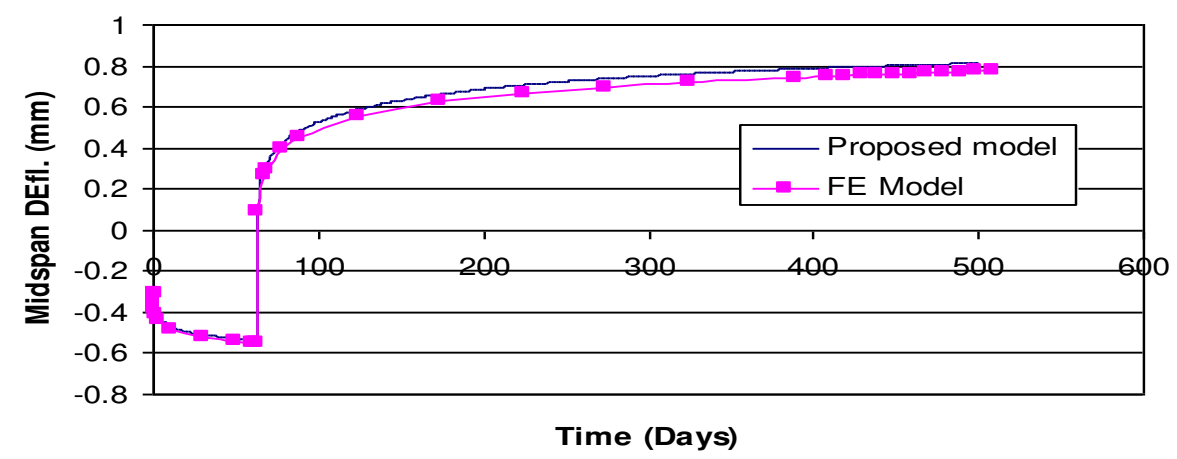

Figure 4. Time dependent midspan displacement for the two models, proposed model and FE model.

\section{Experimental Verification}

The experimental results used in this study correspond to simple beams strengthened by FRP composite materials at bottom and are tested by Saha et al. (2004) and Tan and Saha (2006). Figure 5 shows the dimension of beam, cross-sectional details, and the sustained loads acting on the experimental beams. The material properties for beams are shown in Table 1.

Table 1: properties of materials

\begin{tabular}{|l|l|l|l|l|l|l|l|}
\hline $\begin{array}{l}\text { Beam } \\
\text { designation }\end{array}$ & $\begin{array}{l}E_{c} \\
\mathrm{GPa}\end{array}$ & $\begin{array}{l}\mathrm{E}_{\mathrm{s}} \\
\mathrm{GPa}\end{array}$ & $\begin{array}{l}\mathrm{E}_{\mathrm{p}} \\
\mathrm{GPa}\end{array}$ & $\begin{array}{l}\text { FRP reinforcement } \\
\text { ratio }\end{array}$ & $\begin{array}{l}f_{\text {cu28 }} \\
\mathrm{MPa}\end{array}$ & $\begin{array}{l}f_{t} \\
\mathrm{MPa}\end{array}$ & $\begin{array}{l}\text { Total } \\
\text { load kN }\end{array}$ \\
\hline GB1-59 & 27.2 & 194 & 71 & $0.64 \%$ & 39.5 & 4.67 & 18.8 \\
\hline GB3-49 & 27.2 & 194 & 71 & $1.92 \%$ & 39.5 & 4.67 & 18.8 \\
\hline
\end{tabular}

Note: $f_{c u 28}$ concrete strength at 28 day, $f_{t}$ moudulus of rupture, and $\mathrm{Ec}, \mathrm{E}_{\mathrm{s}}$, and $\mathrm{E}_{\mathrm{p}}$ modulus of elasticity of concrete, steel and GFRP respectively.

Total Load $=18.8 \mathrm{kN}$
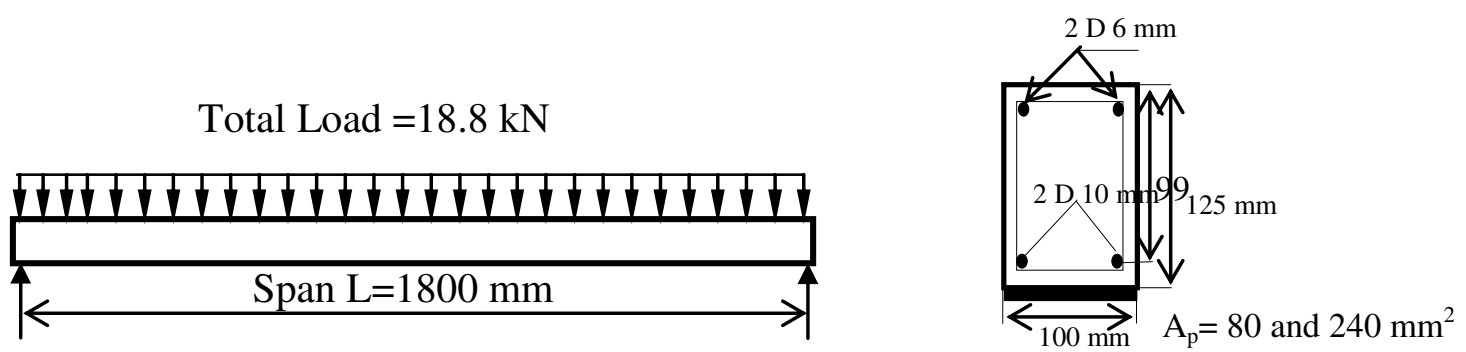

Figure 5: dimension and details of beams (Saha et al. 2004). 


\section{RESULTS AND DISCUSSION}

The loading level for both beams ensures the cracking of the beams. A comparison between the experimental results and analytical results of midspan deflection are shown in figures 6 and 7. It can be noticed from these figures that both of two analytical methods give reasonable agreement to experimental results, however, the proposed method gives closer agreement because it has taken into consideration the tension stiffening effect of concrete, $\beta=1.0$ is considered at this analysis. Saha et al. (2004) used an analytical method that depends on the effective moment of inertia and does not consider the tension stiffening of concrete. Moreover, that method was for pure bending moment and it did not consider the case of prestressing load. The proposed technique gives the instantaneous deflections are 6.5 and 4.8 for GB1-59 and GB3-49 respectively and with time the deflections increase continuously and it reaches 12.36 and $10.44 \mathrm{~mm}$, which are about 1.9 and 2.18 times of the instantaneous deflection for GB1-59 and GB3-49 respectively.

It should be pointed out that the simplified method introduced by the author gives excellent agreement in results for uncracked section and reasonable agreements in results for cracking loads. The divergent of results after cracking loads may be because of many factors, such as the tension stiffening factor, $\zeta$, that need more studies to find a good relation at the case of concrete strengthened with prestressed FRP sheet, and the method of calculating deflection which assumes a parabolic curvature diagram along the span (this assumption may be not accurate at crack sections). This indicates that more studies for long-term behavior of beams strengthened with prestressed FRP sheets are needed especially for cracked sections. Also, this divergent of results may be due to the creep behavior of adhesive layer as mentioned by Diab and Wu (2008).

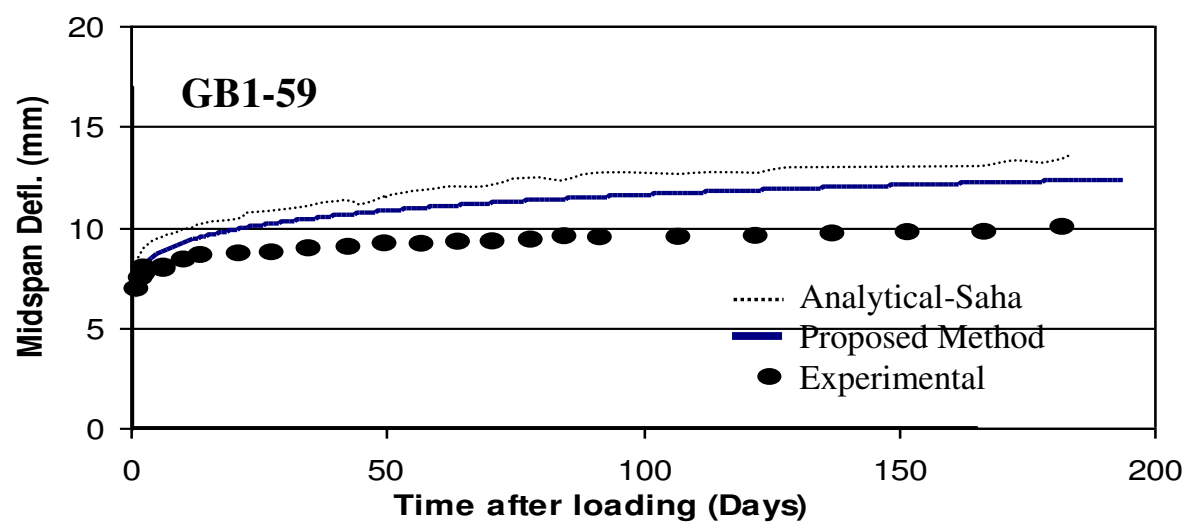

Figure 6 A Comparison between Experimental and analytical deflection at midspan for beam GB1-59 versus time. 


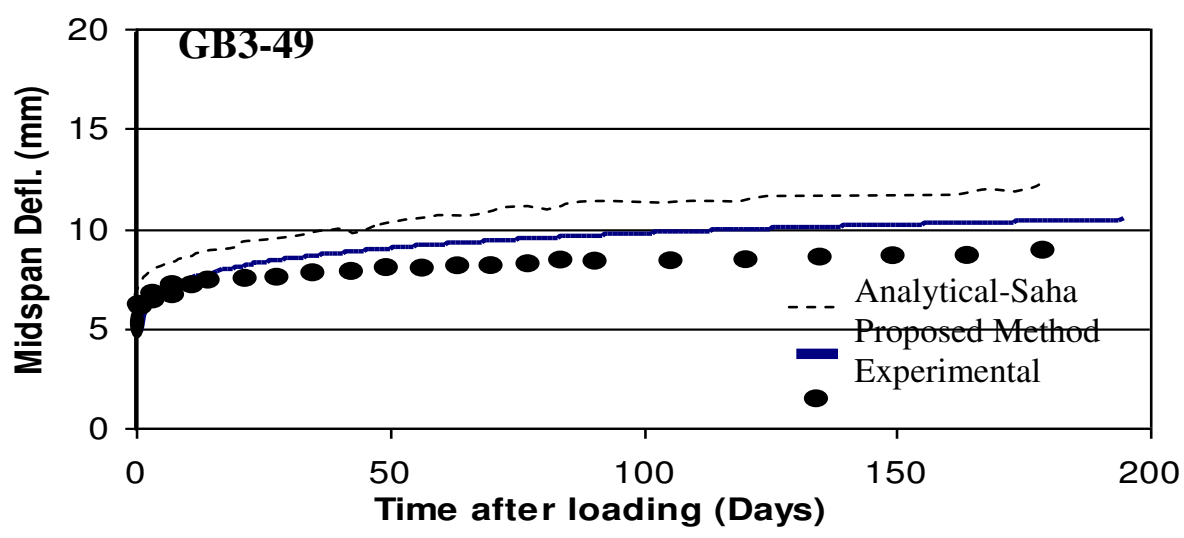

Figure 7 A Comparison between Experimental and analytical deflection at midspan for beam GB3-49 versus time.

\section{CONCLUSION}

A simplified method has been proposed to analyze the long-term behavior of concrete structures strengthened by prestressed or nonprestressed FRP composite materials. This proposed technique can be easily programmed in a personal computer and represents a suitable tool for analyzing the long-term performances of FRP-strengthened concrete structures. This study showed an excellent agreement with DIANA code for uncracked sections, and a reasonable agreement with experimental results for the cracked sections. More studies for beams strengthened with prestressed FRP sheets are needed to carry out to investigate the effect of creep of adhesive and FRP sheets on the long-term deflection of such structures.

\section{REFERENCES}

1- ACI 440.2R-02 (2002). Guide for the design and construction of externally bonded FRP systems for strengthening concrete structures. American Concrete Institute, Redford Station, Detroit, Michigan

2- ACI Committee 435R 1995. Control of deflection in concrete structures. American Concrete Institute, Redford Station, Detroit, Michigan, 66-71.

3- ACI Committee 435R-95 2003. Control of deflection in concrete structures. American Concrete Institute, Redford Station, Detroit, Michigan

4- ACI Committee 440 2001. guide for the design and construction of concrete reinforced with FRP bars. American Concrete Institute, Redford Station, Detroit, Michigan

5- CEB-FIB, 1990, model code for concrete structures, Thomas Telford, london

6- Diab H, Wu Z. (2008). A linear viscoelastic model for interfacial long-term behavior of FRP-concrete interface. Compos B;39:722-30.

7- Diab, H.M and Wu, Z.S. (2007). Nonlinear Constitutive Model for TimeDependent Behavior of FRP-Concrete Interface. Journal of Composite science and Technology, Vol. (67), 2323-2333. 
8- Diab, H.M, and Wu, Z. (2008). A Linear Viscoelastic Model for Interfacial LongTerm Behavior of FRP-Concrete Interface. Composites Part B: Engineering, Composites: part B 39, 722-730.

9- Diab, H.M, Wu, Z.S, and Iwashita, K. (2009). Short and Long-Term Bond Performance of Prestressed FRP Sheet Anchorages. Engineering Structures, Vol. (31), 1241-1249.

10- Ghali, A., Favre, R., and Elbadry, M. 2002.Concrete structures: stress and deformation, $3^{\text {rd }}$ edition, spon press, London and New York.

11- Gilbert R. I., 2001. Shrinkage, cracking and deflection the serviceability of concrete structures. Electric Journal of Structural Engineering.

12- Saha, M. K. and Tan, K. H. (2004). Long-term deflection of FRP-Strengthened beams under sustained loads. FRP Composites in Civil engineering-CICE 2004Seracino(ed)- London.

13- Tan, K.H, and Saha, M.K. (2006). Long-Term Deflections of Reinforced Concrete Beams Externally Bonded with FRP System. Journal composite for construction, 10(6), 474-482.

14- Wu, Z. S., Matsuzaki, T. Fukuzawa, K. and Kanda, T. (2000). Strengthening Effects on Rc Girders with Externally Prestressed Carbon Fiber sheets, Journal of Material , concrete structures and Pavments, JSCE, 153-165.

15- Wu, Z. S., Matsuzaki, T. Fukuzawa, K. and Kanda, T. (2000). Strengthening Effects on Rc Girders with Externally Prestressed Carbon Fiber sheets, Journal of Material , concrete structures and Pavments, JSCE, 153-165.

16- Wu, Z.S., and Diab, H.M. (2007). Constitutive Model for Time-Dependent Behavior of FRP-Concrete Interface. Journal of Composites for Construction, ASCE, Vol. (11), 477-486.

17- Zou, P. X. W. (2003). Long-term properties and transfer length of fiber reinforced polymers. Journal of composites for construction, 7(1), 10-19.

18- Zou, P. X.W. (2003).Theoretical Study on Short-term and long-term deflections Fiber Reinforced polymer prestressed concrete beams. Journal of composites for construction, 7(4), 285-291.

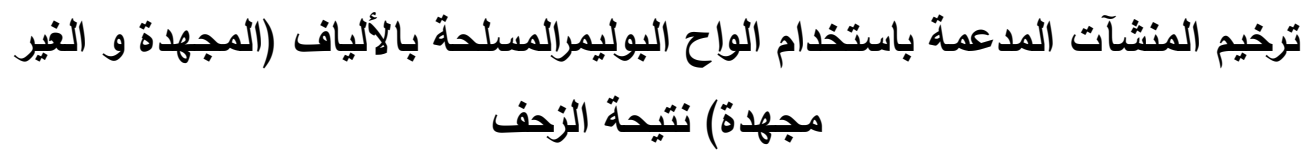

تدعيم المنشآت الخرسانية باستخدام الواح البوليمر المقواة (FRP) تعنبر وسيلة فعالة لتقوية وإعادة

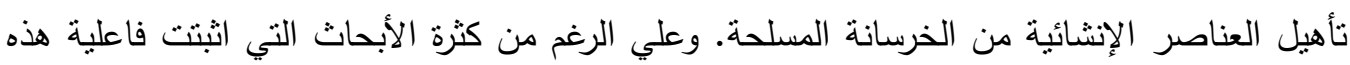

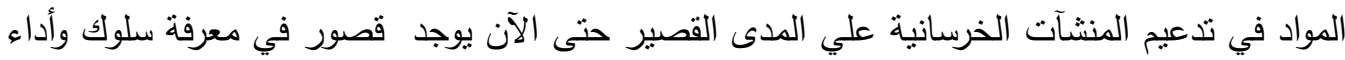
هذه المنشآت المقواة باستخدام الواح البوليمر علي الددي الطويل وخاصة المنشآت المقواة باستخدام ألواح

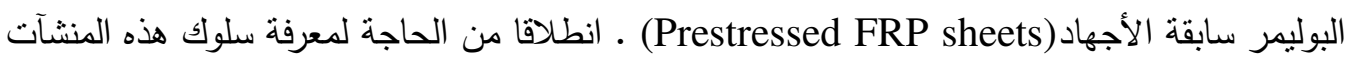

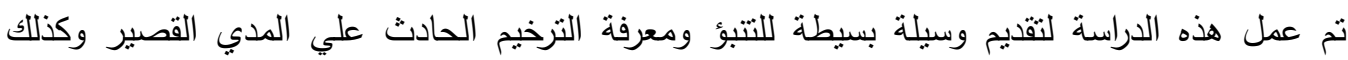


المدى الطويل (short and Long-term deflections) لكل من المنشآت المقواة بالواح البوليمر المجهة او الغير مجهة ( Prestressed or non-prestressed FRP sheets). وفي هذه الدراسة تم استخدام طريقة المعاير الزمني الفعال (The age-adjusted effective لنمزجة زحف الخرسانة ونم استخدام طريقة الاسترخاء لنمزجة زحف ألواح

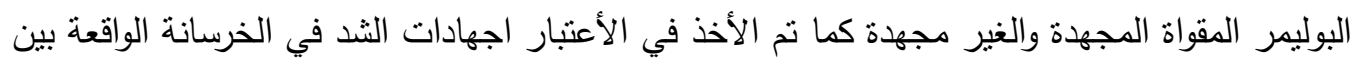

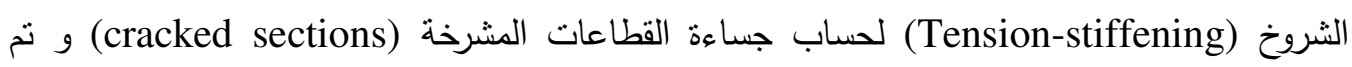
مقارنة نتائج النموذج المقترح فى هذه الدراسة مع نتائج نم الحصول عليها من برنامج يعتمد علي نظرية

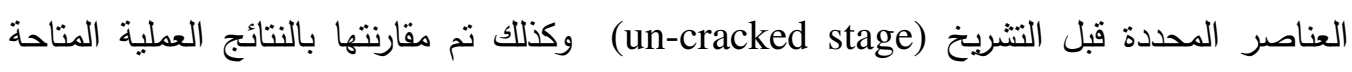
بالأبحاث السابقة و اثبت هذا النموذج نوافقه التام مع النتائج التي نم الحصول عليها باستخدام برنامج العناصر المحددة و كذلك توافق مقبول مع النتائج العملية. 